Journal of Applied Pharmaceutical Science Vol. 5 (11), pp. 031-037, November, 2015

Available online at http://www.japsonline.com

DOI: $10.7324 / J A P S .2015 .501105$

ISSN 2231-3354 (cc) BY-NC-SA

\title{
Production and optimization of antibacterial metabolites from endophytic fungi Nigrospora sp. ML\#3
}

\author{
Kamini Sandey ${ }^{1}$, Ravindra Prasad Aharwal ${ }^{2}$, Suneel Kumar ${ }^{2}$, Sardul Singh Sandhu ${ }^{3 *}$ \\ ${ }^{1}$ Department of Biotechnology, Govt. Nagarjuna PG College of Science, Raipur (C.G.) India. ${ }^{2}$ SGH Center for Rural Biotechnology and Management, \\ Jabalpur, (M.P.) India. ${ }^{3}$ Fungal Biotechnology and Invertebrate Pathology Laboratory, Department of Biological Sciences, Rani Durgavati University, \\ Jabalpur 482001, (M.P.) India.
}

\begin{tabular}{l} 
ARTICLE INFO \\
\hline Article history: \\
Received on: 07/08/2015 \\
Revised on: 07/09/2015 \\
Accepted on: $26 / 09 / 2015$ \\
Available online: $27 / 11 / 2015$ \\
\hline Key words: \\
Endophytic fungi, Bioactive \\
compound, Optimization, \\
Antibacterial activity
\end{tabular}

\section{INTRODUCTION}

Endophytic microorganisms are those that survive inside the living tissues of plants without causing any harmful effects or damages and have symbiotic relationships with host plants (Specian et al., 2012). These endophytes have an ability to produce a variety of secondary metabolites (Sandhu et al., 2014a). Nevertheless, increasing levels of antibiotic resistance in both nonpathogenic and pathogenic bacteria has spurred the search for new antibiotics to manage diseases (Petrini, 1991). Since the population has been increased, this was not possible to afford plant-based medicine. Due to the increasing demand of medicine and destruction of medicinal plants, a huge work carried out in the field of endophytes for producing bioactive compounds that can be used in the treatment of diseases (Onifade, 2007). Endophytes are the synthesizers inside plants that produce bioactive compounds with low toxicity toward

\footnotetext{
* Corresponding Author

Fungal Biotechnology and Invertebrate Pathology Laboratory, Department of Biological Sciences, Rani Durgavati University, Jabalpur 482001, (M.P.) India.Email: ssandhu@rediffmail.com
}

higher plants (Owen and Hundley, 2004). Endophytes provide an extensive variety of bioactive secondary metabolites with unique structure, synthesized via various metabolic pathways i.e. polyketide, isoprenoid, amino acid derivatives (Tan and Zou, 2001).

They have ability to produce a range of secondary metabolites, providing researchers with numerous leads for compounds of antibacterial, antifungal, anticancer, anti-malaria, antioxidant, anti-diabetic and agro-chemical significance, with possible development as new drugs (Strobel, 2003; Gunatilaka et al., 2006). Sandhu et al. (2014b) isolated the endophytic fungi from Calotropis procera (Linn.) R.Br. of Jabalpur region, and tested their antibacterial activity against Escherichia coli, Pseudomonas aeruginosa, Klebsiella pneumonaie, Bacillus subtilis and Staphylococcus epidermidis.

The aim of the present investigation was to study the antibacterial activity and effect of various parameters to gain a high amount of antibacterial bioactive compounds from Nigrospora sp.ML\#3 isolated from A. excelsa Roxb. This plant is commonly known as Maharukh belonging to family Simaroubaceae and the genus is native from southern India. 


\section{MATERIALS AND METHODS}

\section{Collection of plant sample}

Healthy and mature leaves sample of A. excelsa were collected from Hitkarini Engineering College campus, Jabalpur (MP) India in November 2014. The plant sample were placed in sterile plastic bags and brought to the laboratory for isolation of endophytic fungi.

\section{Isolation of the endophytic fungi}

Isolation of endophytic fungi was done according to the methods described by Peterni 1986, with some modifications. Firstly, the plant samples were immersed in $70 \%$ ethanol for 1 minute followed by $4 \% \mathrm{NaOCl}$ for 2 minutes and then sample were rinsed in sterile distilled water. The surplus moisture was blotted in a sterile Whatman no.1 filter paper. Then the four sterilized samples were placed in each Petri plates containing PDA medium amended with Streptomycin. After that, Petri plates were incubated at $26 \pm 1{ }^{\circ} \mathrm{C}$ in fungal incubator for 5 to 7 days. The Petri plates were monitored every day to check the growth of endophytic fungal colonies. The isolates so obtained were transferred on Potato Dextrose Agar slants and preserved at $4^{\circ} \mathrm{C}$ for further studies.

\section{Morphological identification of isolated fungi}

The endophytic fungal isolates were identified based on macroscopic and microscopic characteristics such as color, shape and size of spores, hyphal features and reproductive structures (Subramanian, 1971; Domsch et al., 2007).

\section{Test organisms}

The cultures of test bacteria Bacillus subtilis MTCC441, Escherichia coli MTCC1679, Klebsiella pneumoniae MTCC4032, Salmonella typhimurium MTCC733 and Staphylococcus aureus MTCC96 were obtained from Microbial Type Culture Collection (MTCC) and Gene Bank, Institute of Microbial Technology (IMTECH), Chandigarh, India. The organisms were preserved at $4{ }^{\circ} \mathrm{C}$ in the presence of glycerol $(15 \%, \mathrm{v} / \mathrm{v})$ for longer periods.

\section{Cultivation and extraction}

The fungal isolate was grown in $50 \mathrm{ml}$ Potato Dextrose Broth (PDB) in $250 \mathrm{ml}$ Erlenmeyer flask at $26 \pm 1^{\circ} \mathrm{C}$ in incubator for 14 days under stationary conditions. The broth cultures were filtered with sterile Whatman no. 1 filter paper to separate the filtrate and mycelia. The filtered broth was centrifuged at 6000 $\mathrm{rpm}$ in cooling centrifuged for 10 minute. After centrifugation, metabolite was extracted with the help of solvents like Hexane, Benzene, ethyl acetate and n-Butanol by solvent-solvent extraction procedure. Equal volume of solvent and metabolite were taken in the separating funnel and mixed well by vigorous shaking for 10 to 15 minutes. Separating funnel was allowed to settle until two immiscible layers were formed. The upper layer containing the extracted compounds was separated and collected in another flask. Then the solvent extracts were evaporated in Rotary Vacuum
Evaporator (Buchi R-300 Rotavapor, Buchi Co. Germany). The extract residue was dissolved in de-ionized water and stored at $4{ }^{\circ} \mathrm{C}$ to be used as stock solution for antibacterial activity.

\section{In vitro Antibacterial screening}

For antibacterial activity, Agar Well Diffusion method was performed by standard process (Newyork et al., 1972). Nutrient Agar media (NAM) plates were inoculated with overnight grown bacterial suspension of Bacillus subtilis, Salmonella typhimurium, Eschirichia coli, Streptococcus pyogenes and Klebsiela pneumoniae. The agar wells were prepared by scooping out the media with a sterile cork borer ( $8 \mathrm{~mm}$ in diameter). After that, wells were filled with $80 \mu \mathrm{l}$ of the fungal extract. Then the inoculated plates were incubated at $37^{\circ} \mathrm{C}$ for $24 \mathrm{hrs}$ and the zone of inhibition was recorded by Himedia antibiotic Zone Scale. The zone of inhibition given by the secondary metabolites of fungal isolate was also compared with an antibiotic (streptomycin). Three replicates were carried out for every antibacterial activity test. Mycelia growth rate of the potent strain was determined as dry mycelial weight by drying the cell mass in an oven at $80^{\circ} \mathrm{C}$ overnight and expressed as dry weight of mycelia $(\mathrm{mg} / 50 \mathrm{ml})$.

\section{Optimization of potent fungus for maximum production of bioactive compound Effect of culture media}

To select the suitable growth medium, the potent fungal isolate Nigrospora sp.ML\#3 was grown in different growth media such as Asthana and Hawkers Broth, Czapek's Dox Broth, Potato Dextrose Broth, Richard's Broth and Sabouraud's Dextrose Broth. For bioactive metabolite production, the medium in which the isolate exhibited maximum antibiotic production expressed in terms of zone of inhibition was used as the optimized medium for further study.

\section{Quarantine period}

The time period for the maximum production of antibacterial compound from Nigrospora sp.ML\#3 was studied from one to sixteenth days. The Erlenmeyer flasks containing Potato Dextrose broth was inoculated with fungi and incubated in fungal incubator in stationary condition. The mycelia free culture filtrate was extracted from the first day onwards and antibacterial activity was performed by applying agar well diffusion method.

\section{Effect of pH}

To check the effect of $\mathrm{pH}$ on the production of bioactive compound from Nigrospora sp.ML\#3, $\mathrm{pH}$ ranges were adjusted from 3.0 to 9.0 in the basal medium. After incubation, the metabolites were separated through filter paper, their antibacterial activity was tested against test pathogen, and zone of inhibition was observed.

\section{Effect of Temperature}

Temperature plays a significant role in the production of metabolite from the fungi. Therefore, different temperature ranges 
from $15^{\circ} \mathrm{C}$ to $45^{\circ} \mathrm{C}$ were taken for study the optimum temperature required for growth and production of bioactive metabolite yield. Basal medium was inoculated with $8 \mathrm{~mm}$ diameter of the culture disc and incubated for 14 days. After incubation, the dry mycelia weight and the antibacterial production were recorded.

\section{Statistical analysis}

Values were presented as means \pm SD of at least 3 replicate experiments. Differences between groups analyzed using ANOVA test significant $\mathrm{P}<0.05$ was considered to be statistical significant. Data analysis was conducted using Statistical Package for Social Sciences (SPSS 16.0 version).

\section{RESULT AND DISCUSSION}

\section{Isolation of endophytic fungi}

A total of four endophytic fungi were isolated from healthy leaves of A. excelsa Roxb, which were collected from Hitkarini engineering college Campus, Jabalpur (MP) India as shown in Table 1. Similarly, Sandhu et al. (2014c) isolated 15 species of endophytic fung from Bombex cebia and Argemone mexicana successfully.

Table 1: Endophytic fungi isolated from Ailanthus excelsa Roxb.

\begin{tabular}{cccc}
\hline Local Name & Botanical name & Plant Part & Isolated strain \\
\hline \multirow{3}{*}{ Maharukh } & & & ML\#1 \\
& Ailanthus excelsa & Leaves & ML\#2 \\
& Roxb. & & ML\#3 \\
& & & ML\#4 \\
\hline
\end{tabular}

\section{Morphological identification of Endophytic Fungi}

Slide culture techniques were used for identification of isolated endophytic fungi by using the standard protocol of Subramanian (1971); Domsch et al. (2007). The fungal strains were identified on the basis of macroscopic and microscopic characteristics as seen under the microscope as shown in Fig 1. The following endophytic fungi were identified:

\section{Aspergillus niger (Tiegh.)}

Moderately grown colonies, submerged mycelium, reverse colorless to pale yellow. Exudates limited or lacking with minute droplets, conidial heads large and black globes, conidiophores arising from the substratum varying from $200 \mu \mathrm{m}$ to several millimeters long and $10-20 \mu \mathrm{m}$ diameter, smooth vesicle globose, phialides borne directly on the vesicles in some species.

\section{Alternaria sp.}

Colonies expanding grey to olivaceous, powdery or fatly. Diagnostic characteristics of Alternaria genus include the formation of chains of dark-colored, multi-celled conidia with beaks of tapering apical cells. Conidiophores unbranched, with one or few conidial scars. Conidia are ellipsoidal, with short, cylindrical beak.

\section{Nigrospora sp.}

Mycelium immerged on partly superficial, stroma none, state and hyphodia absent, conidiophores micro filamentous, branched flaxus colorless.

\section{Curvularia lunata (Wakker) Boedjiin}

Colonies effuse, brown, cottony, conidiophores are mononematous, macronematous, straight, often geniculate, sometimes nodose, brown usually smooth. Conidia solitary, acropleurogenous, simple, often curved, clavate, ellipsoidal, broadly fusiform with 3 transverse septa, dark brown, usually the end ones paler than the others, sometimes with dark bands at the septa, hilum scarcely, smooth-walled, middle septum not median,

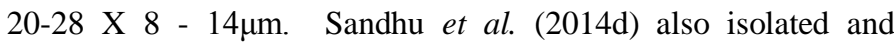
identified 10 fungal species of endophytic fungi including Aspergillus fumigates, Aspergillus japonicas, Aspergillus niger, Fusarium semitectum, Curvularia pallescens, Phoma hedericola, Alternaria tenuissima, Fusarium solani, Drechslera australien and Aspergillus repens from medicinal plant Ricinus communis.

\section{In vitro Antibacterial Activity}

Antibacterial activity was carried out on the ethyl acetate extracts of the four fungal species against the five pathogenic bacteria. The antibacterial activity of the fungal extracts is shown in Table 2 and Fig 2. The values of zone of inhibition were highly variable, ranging between 05-20 mm. Nigrospora sp.ML\#3 showed the maximum zone of inhibition against $K$. pneumoniae (20.26 mm), E. coli $(17.27 \mathrm{~mm})$, B. subtilis $(15.47 \mathrm{~mm}) S$. typhimurium $(12.07 \mathrm{~mm})$ and it gave minimum zone of inhibition against $\quad$ S. pyogenes $(10.20 \mathrm{~mm})$ and the zone of inhibition given by the antibiotic against test bacteria strain (streptomycin) was in the range of between $20.26 \mathrm{~mm}$ and $17.27 \mathrm{~mm}$. Similarly, Curvularia lunata also showed good zone of inhibition against $K$. pneumoniae (16.37 mm), E. coli (15.18 mm), S. pyogenes (12.25 $\mathrm{mm})$, B. subtilis $(10.32 \mathrm{~mm})$ and $S$. typhimurium $(10.28 \mathrm{~mm})$. Other fungi like Aspergillus niger, Alternaria sp. were also observed for their antibacterial activity. Similarly, Sandhu et al. (2014b) isolated 12 endophytic fungi from Calotropis procera (Linn.) R.Br. and evaluate their antibacterial activity against Escherichia coli, Pseudomonas aeruginosa, Klebsiella pneumoniae, Bacillus subtilis and Staphylococcus epidermidis.

Table 2: in vitro antibacterial activity against five pathogenic bacteria.

\begin{tabular}{|c|c|c|c|c|c|}
\hline \multirow{2}{*}{$\begin{array}{c}\text { Name of pathogenic } \\
\text { bacteria }\end{array}$} & \multicolumn{5}{|c|}{ Zone of inhibition (in mm) } \\
\hline & Aspergillus niger & Nigrospora sp. & Alternaria sp. & Curvularia lunata & Streptomycin (1mg/ml) \\
\hline B. subtilis & $05.11 \pm 0.23$ & $15.47 \pm 0.25$ & $08.24 \pm 0.05$ & $10.32 \pm 0.11$ & $16.16 \pm 0.11$ \\
\hline E. coli & $10.43 \pm 0.19$ & $17.27 \pm 0.31$ & $18.11 \pm 0.15$ & $15.18 \pm 0.05$ & $19.20 \pm 0.10$ \\
\hline$K$. pneumoniae & $09.14 \pm 0.25$ & $20.26 \pm 0.10$ & $17.13 \pm 0.19$ & $16.37 \pm 0.31$ & $15.46 \pm 0.15$ \\
\hline S. typhimurium & $12.21 \pm 0.42$ & $12.07 \pm 0.26$ & $10.15 \pm 0.30$ & $10.28 \pm 0.19$ & $17.23 \pm 0.15$ \\
\hline S. pyogenes & $10.15 \pm 0.31$ & $10.20 \pm 0.05$ & $15.19 \pm 0.25$ & $12.25 \pm 0.42$ & $16.40 \pm 0.10$ \\
\hline
\end{tabular}





Fig. 1: Light microscopic (100X) observation of endophytic fungi (A): ML\#1 - Aspergillus niger (B) ML\#2 - Alternaria sp. (C) ML\#3 - Nigrospora sp. (D) ML\#1 - Curvularia lunata

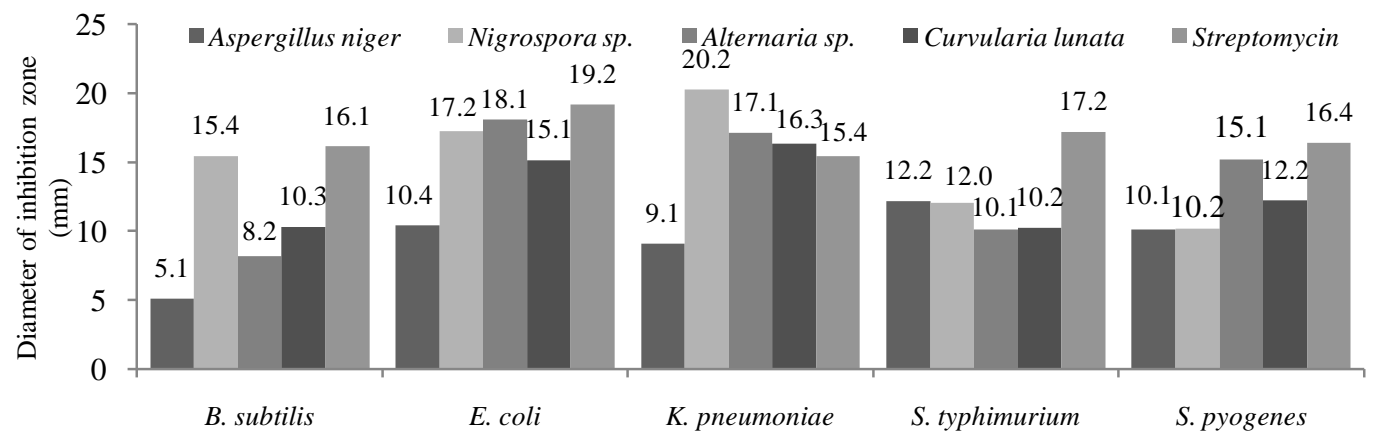

Name of Bacteria

Fig. 2: in vitro antibacterial activity against five pathogenic bacteria.

Table 3: Effect of different quarantine period on biomass and bioactive metabolite production of Nigrospora sp ML\#3.

\begin{tabular}{|c|c|c|c|c|c|c|}
\hline \multirow{2}{*}{$\begin{array}{c}\text { Quarantine } \\
\text { days }\end{array}$} & \multirow{2}{*}{$\begin{array}{c}\text { Dry weight of } \\
\text { mycelia }(\mathrm{g} / 50 \mathrm{ml})\end{array}$} & \multicolumn{5}{|c|}{ Zone of inhibition (in mm) } \\
\hline & & K.pneumoniae & S. typhimurium & B.subtilis & S. pyogenes & E. coli \\
\hline 3 & $0.00 \pm 0.00$ & $00.00 \pm 0.00$ & $00.00 \pm 0.00$ & $00.00 \pm 0.00$ & $00.00 \pm 0.00$ & $00.00 \pm 0.00$ \\
\hline 4 & $0.00 \pm 0.00$ & $00.00 \pm 0.00$ & $00.00 \pm 0.00$ & $00.00 \pm 0.00$ & $00.00 \pm 0.00$ & $00.00 \pm 0.00$ \\
\hline 5 & $0.07 \pm 0.34$ & $08.5 \pm 0.20$ & $09.53 \pm 0.15$ & $00.00 \pm 0.00$ & $00.00 \pm 0.00$ & $00.00 \pm 0.00$ \\
\hline 6 & $0.13 \pm 0.19$ & $10.33 \pm 0.25$ & $09.36 \pm 0.25$ & $00.00 \pm 0.00$ & $11.16 \pm 0.11$ & $00.00 \pm 0.00$ \\
\hline 7 & $0.18 \pm 0.15$ & $11.10 \pm 0.25$ & $10.36 \pm 0.11$ & $00.00 \pm 0.00$ & $12.43 \pm 0.15$ & $00.00 \pm 0.00$ \\
\hline 8 & $0.31 \pm 0.26$ & $13.10 \pm 0.20$ & $12.60 \pm 0.11$ & $00.00 \pm 0.00$ & $12.40 \pm 0.10$ & $00.00 \pm 0.00$ \\
\hline 9 & $0.46 \pm 0.25$ & $13.26 \pm 0.20$ & $14.63 \pm 0.15$ & $00.00 \pm 0.00$ & $13.66 \pm 0.26$ & $09.30 \pm 0.15$ \\
\hline 10 & $0.59 \pm 0.31$ & $14.61 \pm 0.10$ & $16.53 \pm 0.25$ & $00.00 \pm 0.00$ & $13.20 \pm 0.17$ & $09.30 \pm 0.25$ \\
\hline 11 & $0.62 \pm 0.10$ & $16.56 \pm 0.05$ & $17.05 \pm 0.10$ & $12.60 \pm 0.20$ & $14.40 \pm 0.26$ & $12.53 \pm 0.25$ \\
\hline 12 & $0.68 \pm 0.15$ & $19.30 \pm 0.20$ & $17.73 \pm 023$ & $18.36 \pm 0.15$ & $15.56 \pm 0.41$ & $15.23 \pm 0.05$ \\
\hline 13 & $0.67 \pm 0.36$ & $13.23 \pm 0.15$ & $14.40 \pm 0.26$ & $16.40 \pm 0.10$ & $12.46 \pm 0.11$ & $18.66 \pm 0.32$ \\
\hline 14 & $0.61 \pm 0.25$ & $13.36 \pm 0.15$ & $12.36 \pm 0.25$ & $14.33 \pm 0.19$ & $10.33 \pm 0.15$ & $15.40 \pm 0.26$ \\
\hline 15 & $0.45 \pm 0.05$ & $09.50 \pm 0.23$ & $08.36 \pm 0.32$ & $08.43 \pm 0.15$ & $07.50 \pm 0.29$ & $11.23 \pm 0.21$ \\
\hline 16 & $0.19 \pm 0.26$ & $05.51 \pm 0.19$ & $00.00 \pm 0.00$ & $00.00 \pm 0.00$ & $00.00 \pm 0.00$ & $07.25 \pm 0.32$ \\
\hline
\end{tabular}

\section{Optimization of parameters for maximum production of} bioactive compounds

\section{Effect of quarantine period}

The aim of present work was to optimize various physical parameters for maximum production of novel antibacterial bioactive compounds from the isolated fungal isolates. Nigrospora sp. was incubated for 16 days and each day it was observed for the antibacterial activity against pathogenic bacteria. It was found that it gave best result on $12^{\text {th }}$ day of quarantine as shown in Table 3 and Fig 3. Bhattacharyya and Jha, (2011) detect the effect of quarantine period on the production of bioactive compound (Fumonisin B1) by Fusarium moniliforme. Similarly, Stinson, (2003) also observed similar results in the case of endophyte Gliocladium sp.

\section{Effect of culture media}

Five different basal media namely Saboraud's Dextrose Broth (SDB), Richard's Broth (RB), Potato Dextrose Broth (PDB),
Czapex Dox Broth (CDB) and Asthana and Hawker's broth (AHB) media were selected for maximum production of antibacterial bioactive compounds from Nigrospora sp. ML\#3 and SDB was found to be the best media for maximum production of antibacterial bioactive compound against 5 pathogenic bacteria named $K$. pneumoniae $(16.45 \mathrm{~mm}), S$. typhimurium $(12.53 \mathrm{~mm})$, $S$. pyogenes $(12.43 \mathrm{~mm})$ and E. coli $(11.56)$ followed by Potato Dextrose Media.

Maximum mycelial dry weight $(0.67 \mathrm{~g} / 50 \mathrm{ml})$ was also recorded in SDB medium with maximum zone of inhibition (16.45 mm) against $K$. pneumoniae as depicted in Table 4 and Fig 4.

Similarly, Zain et al. (2009) reported that the growth and bioactive metabolites production from Penicillium janthinellum, Penicillium duclauxii and Aspergillus terreus were extensively depended on the type of growth medium and further yeast extract showed the best mycelial growth and bioactive metabolite production. 
Table 4: Effect of different growth media on biomass and bioactive metabolite production of Nigrospora sp. ML\#3

\begin{tabular}{|c|c|c|c|c|c|c|}
\hline \multirow{2}{*}{ Name of Media } & \multirow{2}{*}{$\begin{array}{c}\text { Dry weight of } \\
\text { mycelia }(\mathrm{g} / 50 \mathrm{ml})\end{array}$} & \multicolumn{5}{|c|}{ Zone of inhibition (in mm) } \\
\hline & & K. pneumoniae & S. typhimurium & B. subtilis & S. pyogenes & E. coli \\
\hline AHB* & $0.15 \pm 0.15$ & $08.33 \pm 0.25$ & $00.00 \pm 0.00$ & $06.30 \pm 0.17$ & $07.33 \pm 0.20$ & $05.50 \pm 0.10$ \\
\hline $\mathrm{CDB}^{*}$ & $0.27 \pm 0.47$ & $07.63 \pm 0.15$ & $05.46 \pm 0.20$ & $00.00 \pm 0.00$ & $10.56 \pm 0.15$ & $08.33 \pm 0.05$ \\
\hline $\mathrm{PDB}^{*}$ & $0.45 \pm 0.25$ & $12.30 \pm 0.10$ & $10.26 \pm 0.15$ & $12.66 \pm 0.25$ & $00.00 \pm 0.00$ & $07.43 \pm 0.11$ \\
\hline $\mathrm{RB} *$ & $0.48 \pm 0.26$ & $15.53 \pm 0.25$ & $06.53 \pm 0.11$ & $07.40 \pm 0.30$ & $00.00 \pm 0.00$ & $13.30 \pm 0.17$ \\
\hline $\mathrm{SDB}^{*}$ & $0.67 \pm 0.41$ & $16.45 \pm 0.25$ & $12.53 \pm 0.25$ & $05.50 \pm 0.20$ & $12.43 \pm 0.41$ & $11.56 \pm 0.05$ \\
\hline
\end{tabular}

*Asthana and Hawker's broth (AHB); Czapex Dox broth (CDB); Potato Dextrose broth (PDB); Richard's broth (RB) and Saboraud's Dextrose broth (SDB)

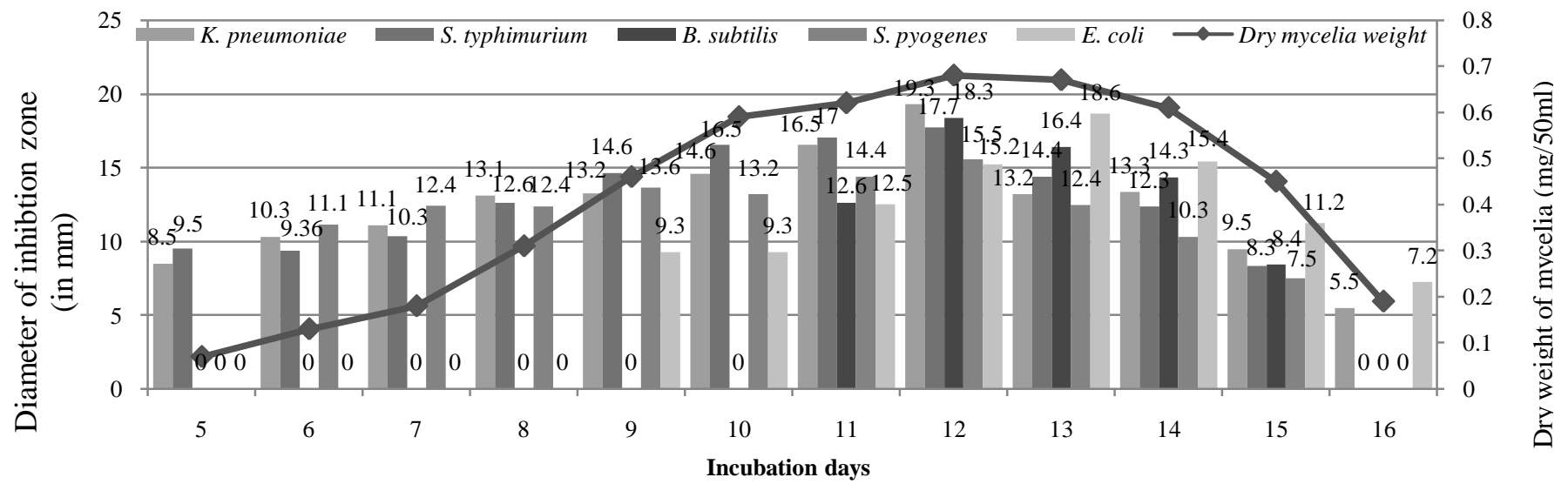

Fig. 3: Effect of different incubation period on biomass and bioactive metabolite production of Nigrospora sp.ML\#3

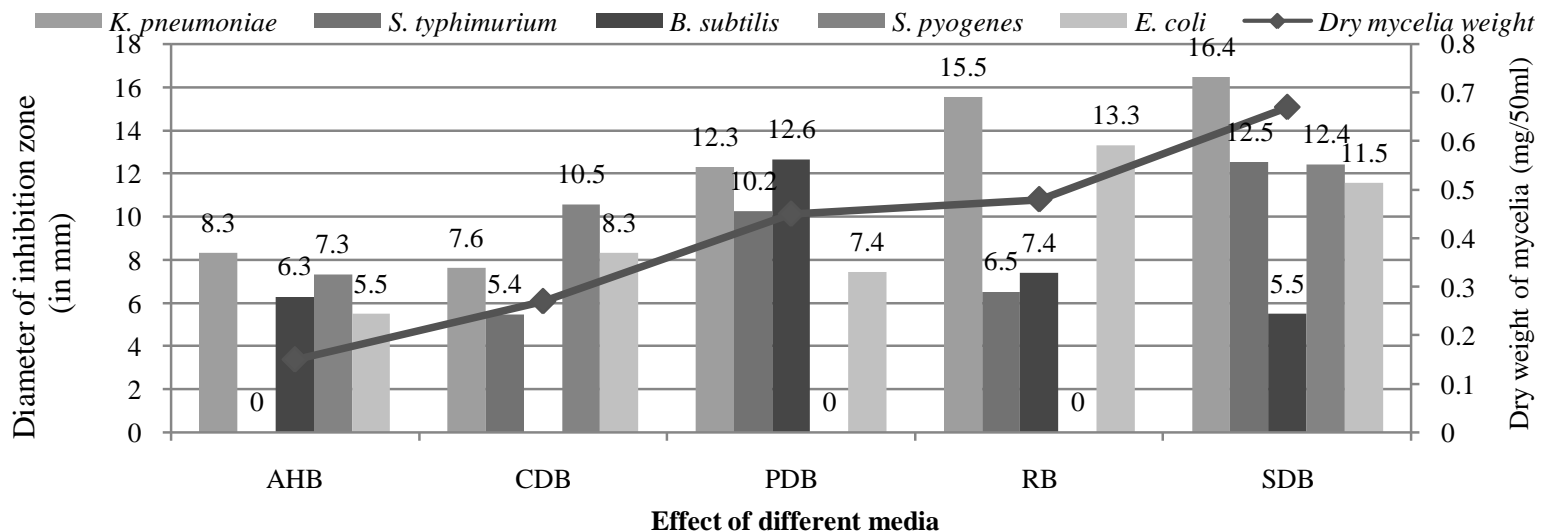

Fig. 4: Effect of different growth media on biomass and bioactive metabolite production of Nigrospora sp.ML\#3

\section{Effect of $p H$}

The production of antibacterial bioactive compounds from endophytic fungi was observed on different $\mathrm{pH}(3,4,5,6,7$, 8 and 9). The result indicated that $\mathrm{pH} 7.0$ was suitable for growth and maximum production of antibacterial bioactive compound from Nigrospora sp.ML\#3. It showed highest zone of inhibition against $K$. pneumoniae $(20.30 \mathrm{~mm}) S$. typhimurium $(17.50 \mathrm{~mm}), B$. subtilis $(14.26 \mathrm{~mm})$, S. pyogenes $(16.60 \mathrm{~mm})$ and E. coli $(13.46$ $\mathrm{mm})$ as depicted in Table 5 and Fig 5. Maximum mycelial growth $(0.57 \mathrm{~g} / 50 \mathrm{ml})$ was also recorded at $\mathrm{pH} 7.0$ and minimum growth and antibacterial activity was observed at $\mathrm{pH}$ 4.0. Similarly, Jain and Pudir, (2011) reported the maximum bioactive metabolite production by Aspergillus terreus in Potato Dextrose broth at $\mathrm{pH}$ 6.0. Gogoi et al. (2008) studied the influence of $\mathrm{pH}$ on the growth and production of bioactive metabolite by an endophyte Hypocrea sp.NSF-08 isolated from Dillenia indica Linn. in North-East, India. Similarly, Digrak and Eluk, (2011) also observed the highest production of biomass by $F$. equiseti at $\mathrm{pH} 8$, while maximum toxic metabolite was produced at the $\mathrm{pH} 5$.

\section{Effect of temperature}

For maximum production of bioactive compounds from fungi Nigrospora sp.ML\#3, it was incubated at different temperature $(15,20,25,30,35,40$ and 45$)$. Increase in quarantine period from $20^{\circ} \mathrm{C}$ to $30^{\circ} \mathrm{C}$ enhanced the growth and production of bioactive metabolite. Maximum mycelia growth $(0.71 \mathrm{~g} / \mathrm{ml})$ and zone of inhibition was observed at $25^{\circ} \mathrm{C}$ against $K$. pneumoniae $(21.53 \mathrm{~mm})$, S. typhimurium $(21.36 \mathrm{~mm})$, S. pyogenes $(15.50 \mathrm{~mm})$ and B. subtilis $(14.30 \mathrm{~mm})$ as shown in Table 6 and Fig 6. However, minimum zone of inhibition was observed against $E$. coli $(12.60 \mathrm{~mm})$. Bhattacharyya and Jha, (2011) reported that, the increase of the incubation temperature from $25^{\circ} \mathrm{C}$ to $30^{\circ} \mathrm{C}$ enhanced the growth of mycelia and production of bioactive metabolite in Aspergillus strain. 
Table 5: Effect of different $\mathrm{pH}$ on biomass and bioactive metabolite production of Nigrospora sp.ML\#3

\begin{tabular}{cccccc}
\hline pH & Dry weight of & \multicolumn{4}{c}{ Zone of inhibition (in mm) } \\
\cline { 3 - 6 } & mycelia $(\mathbf{g} / \mathbf{5 0 m l})$ & K. pneumoniae & S. typhimurium & B. subtilis & S. pyogenes \\
\hline 3.0 & $0.00 \pm 0.00$ & $00.00 \pm 0.00$ & $00.00 \pm 0.00$ & $00.00 \pm 0.00$ & $00.00 \pm 0.00$ \\
4.0 & $0.05 \pm 0.19$ & $00.00 \pm 0.00$ & $09.36 \pm 0.15$ & $00.00 \pm 0.00$ & $08.36 \pm 0.15$ \\
5.0 & $0.28 \pm 0.25$ & $12.60 \pm 0.10$ & $09.50 \pm 0.20$ & $13.33 \pm 0.20$ & $11.50 \pm 0.10$ \\
6.0 & $0.32 \pm 0.31$ & $17.36 \pm 0.15$ & $14.30 \pm 0.10$ & $15.33 \pm 0.05$ & $15.50 \pm 0.10$ \\
7.0 & $0.57 \pm 0.24$ & $20.30 \pm 0.26$ & $17.50 \pm 0.10$ & $14.26 \pm 0.15$ & $16.60 \pm 0.20$ \\
8.0 & $0.35 \pm 0.15$ & $10.43 \pm 0.11$ & $12.16 \pm 0.11$ & $12.56 \pm 0.05$ & $11.53 \pm 0.05$ \\
9.0 & $0.13 \pm 0.10$ & $00.00 \pm 0.00$ & $08.33 \pm 0.25$ & $09.56 \pm 0.05$ & $00.00 \pm 0.00$ \\
\hline
\end{tabular}

Table 6: Effect of different temperature on biomass and bioactive metabolite production of Nigrospora sp.ML\#3

\begin{tabular}{|c|c|c|c|c|c|c|}
\hline \multirow{2}{*}{$\begin{array}{l}\text { Temp. } \\
\left({ }^{\circ} \mathrm{C}\right)\end{array}$} & \multirow{2}{*}{$\begin{array}{c}\text { Dry weight of } \\
\text { mycelia }(\mathrm{g} / 50 \mathrm{ml})\end{array}$} & \multicolumn{5}{|c|}{ Zone of inhibition (in mm) } \\
\hline & & K. pneumoniae & S. typhimurium & B.subtilis & S.pyogenes & E.coli \\
\hline 15 & $0.06 \pm 0.37$ & $10.33 \pm 0.15$ & $05.46 \pm 0.15$ & $07.43 \pm 0.05$ & $00.00 \pm 0.00$ & $00.00 \pm 0.00$ \\
\hline 20 & $0.34 \pm 0.15$ & $15.43 \pm 0.23$ & $11.43 \pm 0.11$ & $09.80 \pm 0.10$ & $10.36 \pm 0.15$ & $05.56 \pm 0.05$ \\
\hline 25 & $0.71 \pm 0.23$ & $21.53 \pm 0.25$ & $21.36 \pm 0.15$ & $14.30 \pm 0.02$ & $15.50 \pm 0.10$ & $12.60 \pm 0.10$ \\
\hline 30 & $0.37 \pm 0.25$ & $09.30 \pm 0.10$ & $00.00 \pm 0.00$ & $12.63 \pm 0.15$ & $11.53 \pm 0.15$ & $10.63 \pm 0.34$ \\
\hline 35 & $0.19 \pm 0.37$ & $06.36 \pm 0.05$ & $00.00 \pm 0.00$ & $05.53 \pm 0.11$ & $00.00 \pm 0.00$ & $07.40 \pm 0.26$ \\
\hline 40 & $0.03 \pm 0.10$ & $00.00 \pm 0.00$ & $00.00 \pm 0.00$ & $00.00 \pm 0.00$ & $00.00 \pm 0.00$ & $00.00 \pm 0.00$ \\
\hline
\end{tabular}

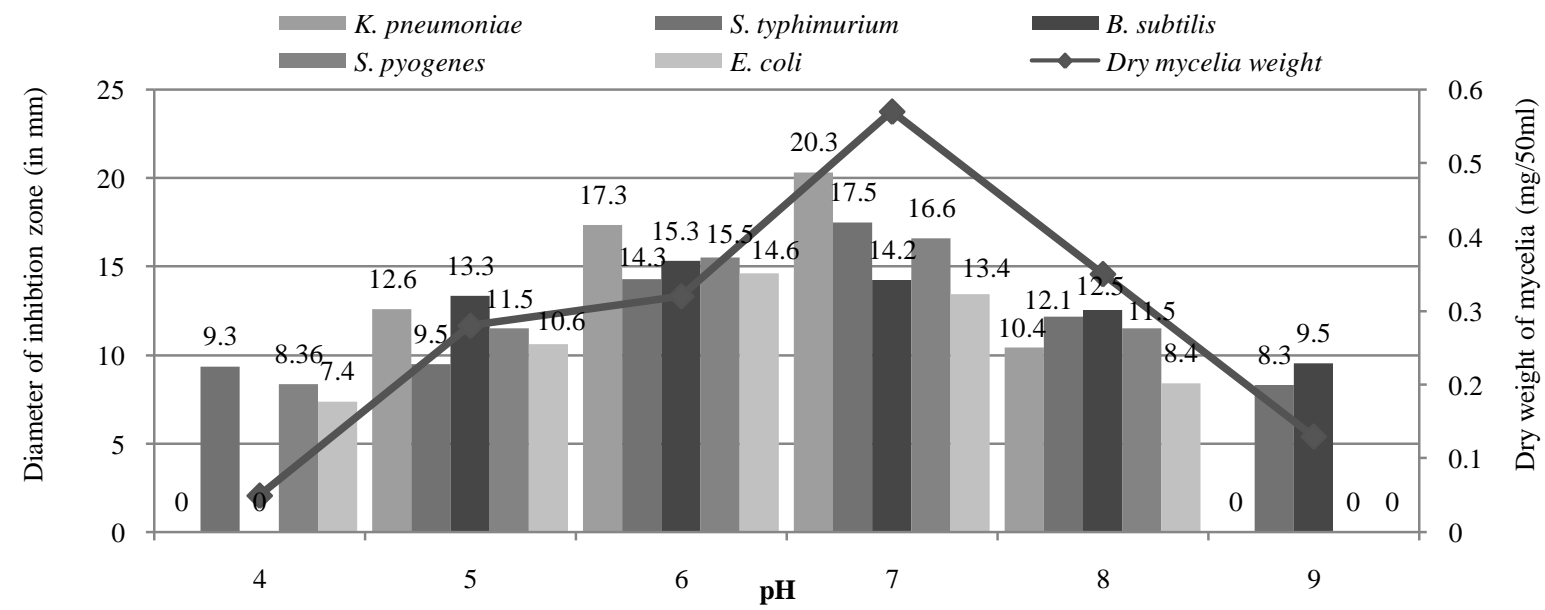

Fig. 5: Effect of different $\mathrm{pH}$ on biomass and bioactive metabolite production of Nigrospora sp.ML\#3.

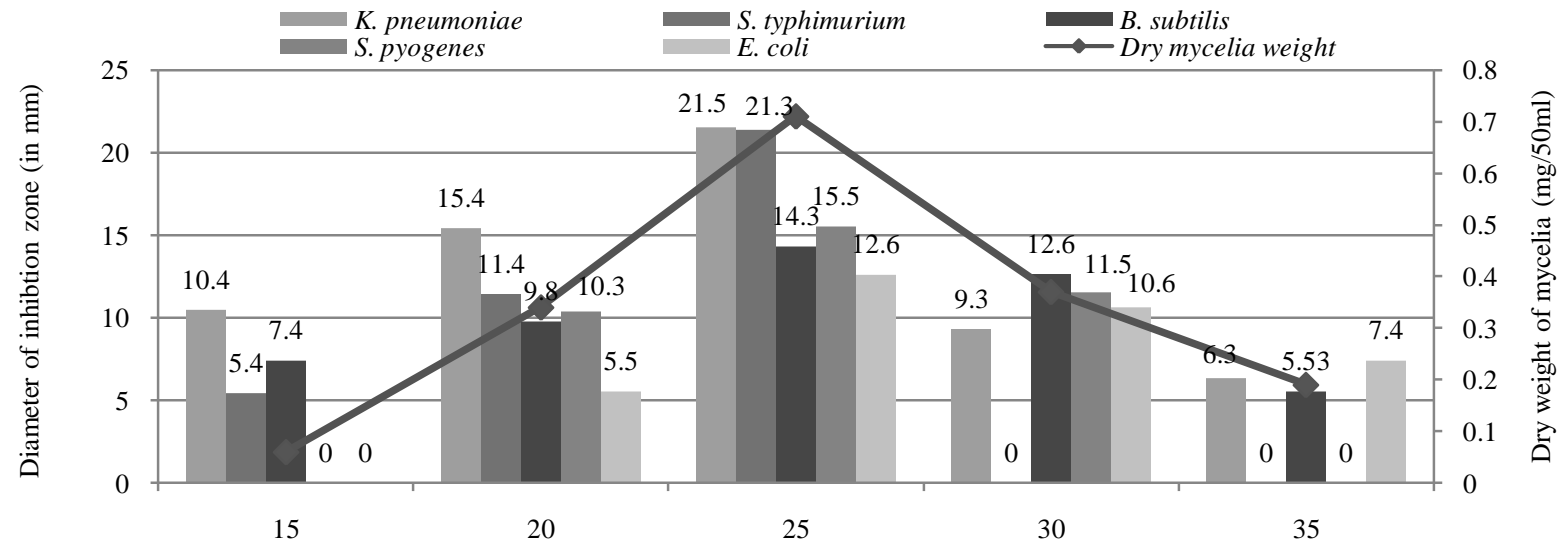

Temperature (oC)

Fig. 6: Effect of different temperature on biomass and bioactive metabolite production of Nigrospora sp. ML\#3

\section{CONCLUSION}

A total four endophytic fungi Aspergillus niger, Nigrospora sp., Aspergillus sp. and Curvularia lunata was isolated from the medicinal plant A. excelsa. The endophyte Nigrospora sp. ML\#3 has showed greater antibacterial activity against five pathogenic bacteria in this study. The maximum production of the anti-bacterial metabolites by Nigrospora sp. was achieved by optimizing various parameters like media (SDB), quarantine period (12 days), temperature $\left(25^{\circ} \mathrm{C}\right)$ and $(\mathrm{pH} 7)$ under aseptic conditions were found to be optimum for the maximal production of bioactive metabolite. These findings will assist in formulating a suitable culture medium for production of the antibacterial compound from Nigrospora sp. and further prospectus of this 
study can be applied in drug production like antibiotics. Our study reports the optimization of still culture conditions for the maximum growth and production of bioactive secondary metabolite compounds from Nigrospora sp. ML\#3.

\section{ACKNOWLEDGEMENT}

The authors wish to thanks the Director of SGHRBM, Mrs. Ranjeet Kaur Sandhu Jabalpur, India for providing laboratory facility and the Head, Department of Biotechnology, Govt. Nagarjuna PG College of Science, Raipur (C.G.) India for dissertation leave to Kamini Sandey.

\section{REFERENCES}

Bhattacharyya PN, Jha DK. optimization of cultural conditions affecting growth and improved bioactive metabolite production by a subsurface Aspergillus strain TSF146. Int J Appl Bioly Pharm Tech, 2011;2(4): 133-145.

Digrak M, Eluk SZ. Determination of some fungal metabolite as influenced by temperature, time, $\mathrm{pH}$ and sugars by bioassay method. Turk J Bio, 2001;25:197-203.

Domsch KH, Gams W, Anderson TH. 2007. Compendium of soil fungi. 2nd ed. IHW-Verlag, Eching, Germany.

Gogoi DK, Deka Boruah HP, Saikia R, Bora TC. Optimization of process parameters for improved production of bioactive metabolite by a novel endophytic fungus Fusarium sp. DF2 isolated from Taxus wallichiana of North East India. World J Microbiol Biotechnol, 2008;24:79-87.

Gunatilaka AAL. Natural products from plant-associated microorganisms: distribution, structural diversity, bioactivity, and implications of their occurrence. J Natl Prod, 2006;69:(3)509-526.

Jain P, Pundir RK. Effect of fermentation medium, $\mathrm{pH}$ and temperature variations on antibacterial soil fungal metabolite production. J Agric Technol, 2011;7:247-269.

Newyork NY, Barnett HL, Hunter BB. 1972. Illustrated genera of imperfecti fungi. Burgers Company, Minneapolis.

Onifade AK. Research trends: Bioactive metabolites of fungal origin. J Biol Sci 2007;2:81-84.

Owen NL, Hundley N. Endophytes the chemical synthesizers inside plants. Sci Prog, 2004; 87:79-99.

Petrini O. 1986. Taxonomy of endophytic fungi of aerial plant tissues. In: Microbiology of the phylospere. Fokkenna NJ, Van Den Heuvel J. ed. Cambridge University Press, Cambridge 175-187.
Petrini O. 1991. Fungal endophytes of tree leaves. In: Andrews J, Hirano SS, ed. Microbial ecology of leaves. New York: Springer 179197.

Sandhu SS, Kumar S, Aharwal RP. Isolation and Identification of endophytic fungi from Ricinus communis Linn. and their antibacterial activity. Int J Res Pharm Chem, 2014d;4(3): 611-618.

Sandhu SS, Aharwal RP, Kumar S. Isolation and antibacterial property of endophytic fungi isolated from Indian medicinal plant Calotropis procera Linn. World J Phar Pharmac Sci, 2014b; 3(5): 678-691.

Sandhu SS, Kumar S, Aharwal RP, Kumar S. Isolation and detection of anti-bacterial activity of endophytic fungi from Bombex cebia and Argemone Mexicana. J Chem Pharma Res, 2014c; 6(11):95-100.

Sandhu SS, Suneel K, Aharwal RP, Shukla H and Rajak RC. Endophytic Fungi: As A Source of Antimicrobials Bioactive Compounds World J Phar Pharm Sci, 2014a;3(2):1179-1197.

Specian V, Sarragiotto MH, Pamphile JA, Clemente E. chemical characterization of bioactive compounds from the endophytic fungus Diaporthe helianthi isolated from luehea divaricata. Braz J Microbiol 2012;1174-1182.

Stinson M, Ezra D, Hess WM, Sears J, Strobel G. An endophytic Gliocladium sp. of Eucryphia cordifolia producing selective volatile antimicrobial compounds. Plant Sci 2003; 165:913-922.

Strobel G. Endophytes as sources of bioactive products. Microbes Infect, 2003;5:535-544.

Subramanian CV. 1971. Hypomycetes an account of Indian species except Cercospora. New Delhi India: Indian Council of Agricultural Research Publication.

Tan RX, Zou WX. Endophyres: a rich source of functional metabolites. Nat Prod Rep, 2001;18;4:448-459.

Zain ME, Razak AA, El-Sheikh HH, Soliman HG, Khalil AM. Influence of growth medium on diagnostic characters of Aspergillus and Penicillium species. Afr J Microbiol Res, 2009;3(5):280-286.

\section{How to cite this article:}

Kamini Sandey, Ravindra Prasad Aharwal, Suneel Kumar, Sardul Singh Sandhu. Production and optimization of Antibacterial metabolites from endophytic fungi Nigrospora sp.ML\#3. J App Pharm Sci, 2015; 5 (11): 031-037. 